


\title{
Treinta años de aspiraciones constitucionales de paz para el cambio social*
}

\author{
Juan Carlos Ospina** \\ David Fernando Cruz ${ }^{* * *}$
}

"Pocas veces ha sido tan cierto que estamos reformando para pacificar. A la violencia, el odio y la impunidad, le hemos opuesto la transformación pacífica, la reconciliación y la justicia. La tarea, claro está, aún no culmina. Ahora, tenemos que demostrar que aquello que soñamos, aquello por lo cual tanto luchamos, no solo es posible en un texto constitucional, sino también en la realidad".

César Gaviria Trujillo, 4 de julio de 1991.

\begin{abstract}
Resumen
La Constitución de 1991 está llena de aspiraciones. Una de las fundamentales, dada la situación de conflicto armado y de crisis de derechos humanos del país, es la de alcanzar la paz. Sin embargo, luego de 30 años, existe la sensación de que dicha aspiración no se va a poder alcanzar. En este artículo sostenemos que esta sensación se arraiga en que la paz se presenta como un deseo tan inabarcable como inalcanzable, sin vías de concreción, y también surge, de visiones generales que nos dicen muy poco del cambio social que queremos lograr. Por esa razón, asumimos que hay disputas legitimas en las diferentes manifestaciones constitucionales de la paz, proponemos abordar la paz desde la convivencia pacífica, y valoramos si algunas de las transformaciones que permitió la Constitución dan razones para la esperanza o la desesperanza en esta materia.
\end{abstract}

Palabras clave: paz; Constitución; convivencia; cambio social; aspiraciones constitucionales.

\section{Thirty years of constitutional aspirations for peace for social change}

\section{Abstract}

The 1991 Constitution is full of aspirations. One of the main ones, given the inter armed conflict and the human rights crisis of the country, is to reach peace. Nevertheless, after thirty years, there is a social sense that the peace aspiration could not be reached. In this article, we argue that this sense originates in a particular understanding of peace as a wish so unembraceable as unreachable, without ways of realization, and from general visions that say little about the social change that we want to achieve. Therefore, we assume that there are legitimate disputes in the different constitutional peace manifestations, we propose to address peace from coexistence, and we evaluate if there are some transformations driven by the Constitution that give us reasons for hope or hopelessness in this matter. Keywords: Peace; Constitution; coexistence; social change; constitutional aspirations

\section{Trinta anos de aspirações constitucionais de paz para a mudança social}

\section{Resumo}

A Constituição de 1991 está repleta de aspirações. Uma das fundamentais, devido à situação de conflito armado e da crise de direitos humanos no país, é a de alcançar a paz. Porém, depois de 30 anos, existe a sensação de que tal aspiração não será possível realizar. Neste artigo, sustentamos que este sentimento que se sustenta em que a paz apresenta-se como um desejo tão inacessível como inatingível, sem possibilidades de concretização, e a partir de visões gerais que nos mostram muito pouco da mudança social que queremos realizar. Por esta razão, assumimos que existem disputas legítimas nas diferentes manifestações constitucionais da paz, propomos abordar a paz desde a convivência pacífica e avaliamos se algumas das transformações permitidas pela Constituição justificam a esperança ou desesperança nesta matéria.

Palavras-chave: Paz; Constituição; Convivência; Mudança social; Aspirações constitucionais.

\section{* $\quad$ Artículo de reflexión}

** Profesor de Cátedra y doctorando en derecho de la Universidad de los Andes, Colombia. Abogado, especialista en cultura de paz y Magister en derechos humanos. Correo electrónico: jc.ospinar1@uniandes.edu.co ORCID: https:// orcid.org/0000-0002-5587-1220

*** Profesor de Cátedra y doctorando en derecho de la Universidad de los Andes, Colombia. Abogado de la Universidad Nacional. Magister en derecho. Correo electrónico: df.cruz@uniandes.edu.co ORCID: https://orcid.org/0000-00016194-9955

Cómo citar este artículo: Ospina, J. C. y Cruz, D. F. (2021). Treinta años de aspiraciones constitucionales de paz para el cambio social, Estudios de Derecho, 78 (172), 197-219

DOI: 10.17533/udea.esde.v78n172a08

Fecha de recepción: 04/02/2021 Fecha de aceptación: 20/05/2021 


\section{Treinta años de aspiraciones constitucionales de paz para el cambio social}

\section{Introducción}

El presente artículo aborda una de las materias más gaseosas de la construcción constitucional de 1991: la paz. La razón de su estado gaseoso se deriva de las pocas delimitaciones constitucionales y las amplias aproximaciones que desde el derecho y la política han capturado las vías de su concreción. Hacer realidad la paz exige la unión de perspectivas transdiciplinarias, compromiso social y apuestas siempre incompletas, en la vía de la utopía.

Las aspiraciones constitucionales incluidas en el texto de 1991 son las respuestas a la situación distópica en la que se encontraba el país. El conflicto armado, la incapacidad estatal y la debilidad democrática, que alimentaba, a su vez, la violencia política, eran elementos indeseables que debían superarse con ayuda del texto constitucional. Los contrastes en estas materias son complejos dada la continuidad de la violencia y los problemas que enfrentan las democracias en la actualidad, pero necesarios para marcar un antes y un después constitucional.

La promesa de cambio social, impulsado por amplios sectores y apoyado por las élites en el poder, se consolidó en el texto constitucional. El proceso enfocado en cambiar la estructura del sistema social, a pesar de mantener algunos de sus elementos, motivó nuevas actitudes y expectativas frente al Estado y el derecho. Las consecuencias en el funcionamiento del sistema social, derivadas de los cambios institucionales estructurales incluidos en la Constitución, afianzaron la confianza en transformaciones cercanas. Sin embargo, el cambio social derivado de una Constitución toma el tiempo que tome la consolidación del compromiso social y la construcción de vías de materialización. El adagio popular diría: "todo el mundo habla de paz, pero nadie se compromete".

De acuerdo con lo anterior, aunque los procesos constituyentes son en esencia escenarios de quiebre institucional, político y jurídico, el cambio social no se produce automáticamente. El mantenimiento del elenco, así como de sus capacidades y actitudes, y la concentración del poder, especialmente el presidencialismo y las políticas que hacen cíclica la desigualdad, relativizaron el cambio social derivado 
de la Constitución. Igualmente, el encause institucional de los conflictos sociales se fue desbordando, como se ha planteado una y otra vez en relación con la mora judicial, y la permanencia de la violencia se fue haciendo más clara. La garantía de no repetición es la aspiración última de la Constitución para la paz.

Con estas consideraciones preliminares, a continuación, analizaremos los escenarios y alcances de las aspiraciones constitucionales para la paz y el cambio social. Para ello, en una primera parte reconstruimos la comprensión de la constituyente y la Constitución para la paz. Luego, abordamos lo que denominamos el conflicto de aspiraciones, derivado de las diversas aproximaciones sobre el derecho a la paz y su posible convergencia. Finalmente, presentamos algunas razones para la esperanza y la desesperanza en el cambio social para la paz.

\section{La constituyente y la Constitución por la paz}

La Constitución de 1991 surgió como respuesta a la desesperanzadora marcha de la violencia. Desde los años 60 se empezaron a gestar las fuerzas que décadas después impulsarían la transformación constitucional. A las espaldas del Estado empezaban a tomar más fuerza y relevancia una variedad considerable de grupos armados. El M-19 trasladó el telón de operaciones subversivas, de los campos y montañas, a las ciudades del país, alertando a la clase urbana sobre las nuevas dimensiones del conflicto. Por otro lado, las gestas de los apodados mágicos se empezaban a visibilizar en la sociedad. Al principio fueron solo unos relatos curiosos y excéntricos de nuevos millonarios, después saltaron a carteles de alcance nacional liderados por carismáticos narcotraficantes que terminarían cautivando y absorbiendo la lealtad de diversos sectores de la población (Duncan, 2015).

A su vez, los años previos serían de infancia para una generación urbana que no comprendía las raíces ni los alcances del conflicto ${ }^{1}$. Vivían en un país relativamente tranquilo que a hurtadillas les permitía explorar su juventud (González Jácome, 2019; Lemaitre, 2009). Posteriormente, esta misma generación sería la que caracterizaría realmente al país, no el violento que se presenta comúnmente, sino el de la huida ante la guerra (Lemaitre, 2019) y el del silencio (De Gamboa y Uribe, 2017).

El 6 de noviembre de 1985, ante los ojos de una generación que apenas tomaba conciencia de la escala del conflicto en el que estaba inmerso su país, un grupo de

1 Jorge González Jácome en su libro: Revolución, Democracia y Paz. trayectorias de los derechos humanos en Colombia (1973-1985), muestra como los años 70 permitieron la confluencia entre el discurso de los derechos humanos y las utopías de izquierda. El discurso de los derechos humanos sirvió como resorte de las movilizaciones sociales que se adelantaron en estos años y permearon el imaginario de la movilización social. 
guerrilleros del M-19 se tomó el Palacio de Justicia en el centro de Bogotá, en la denominada operación Antonio Nariño por los Derechos del Hombre. La reacción del ejército fue feroz: a las pocas horas del inicio de la toma se posicionaron una fila de tanques en la Plaza de Bolívar que terminarían disparando contra uno de los costados del edificio. El Palacio ardió, el fuego no cesó. La toma y retoma del Palacio inauguraron una espiral de violencia que alcanzó también a los funcionarios del Estado y la clase política. Policías, defensores, ministros y candidatos presidenciales, entre otros, murieron y una generación tomó el exilio como huida digna ante el horror. La sensación de que todo en el Estado estaba en riesgo era generalizada.

En 1988 se impulsó desde el Gobierno nacional un programa de cambio constitucional a través de referendo que no despertó simpatía entre los líderes políticos ${ }^{2}$, pero que luego logró un acuerdo político entre liberales y conservadores. Parte de esta reforma incluía, por primera, vez la figura de la Corte Constitucional y buscaba un soporte democrático para empezar un proceso constituyente. El palo en la rueda fue el Consejo de Estado que consideró que el acuerdo político celebrado era un acto administrativo preparatorio del referendo, que a su vez era un mecanismo que no contemplaba la Constitución para su cambio, por lo que resultaba inconstitucional ${ }^{3}$ (Fonnegra González, 1988).

El asesinato de Luis Carlos Galán, la noche del 18 de agosto de 1989, multiplicó la indignación social. No fueron los votos sino las balas las que pusieron fin a su carrera política. Su muerte fue el catalizador de la exigencia de cambio -en parte porque su muerte simbolizaba muchas más ${ }^{4}$. Cuando su cuerpo cayó en la plaza de Soacha, se levantó una generación en el país. Las calles se inundaron de estudiantes que marchaban en contra de la violencia.

La potencia del movimiento estudiantil radicó en la alegría y la esperanza, como diría Catalina Botero 28 años después ${ }^{5}$. Mientras que las élites desconcertadas no podían reaccionar a los ataques del narcotráfico, los estudiantes se organizaban en distintas universidades para pedir un cambio. Al principio, marcharon en silencio, después discutieron y en el calor del intercambio de opiniones empezó a

2 Expresidentes como Carlos Lleras Restrepo y López Michelsen se mostraron reticentes ante la posibilidad de este cambio constitucional.

3 Maite Fonnegra González, en un estudio sobre el plebiscito del 1988, argumenta que a pesar de que la decisión del Consejo de Estado estaba plagada de imprecisiones, fue un mecanismo efectivo para reducir el poder del presidente Barco que, a través de la agenda de reforma a la Constitución, estaba acaparando poder institucional y disminuyendo la fortaleza del Congreso.

4 En la elección presidencial de 1990 fueron asesinados 3 candidatos presidenciales: Bernardo Jaramillo Osa, Luis Carlos Galán y Carlos Pizarro Leongómez. A esto se suma una larga de lista de jueces, policías y muchos otros funcionarios públicos asesinados.

5 Estas palabras las dijo siendo Decana de la Facultad de Derecho de la Universidad de los Andes en un evento sobre la séptima papeleta y el movimiento estudiantil celebrado en la universidad de los Andes a finales del 2019. 
tomar fuerza la idea de que se necesitaba una profunda renovación constitucional ${ }^{6}$ (García Jaramillo, 2015; Lemaitre, 2009). Un pacto para frenar la violencia.

La fallida reforma de 1988 allanó el camino del movimiento estudiantil. La necesidad de un cambio constitucional ya se había posicionado en la opinión pública y se conocía su principal obstáculo: la resistencia jurídica al cambio de la Constitución de $1886^{7}$ debido a su rigidez ${ }^{8}$. Sin embargo, las circunstancias políticas habían variado. Ya no era el presidente quien impulsaba el cambio constitucional, sino un movimiento estudiantil que se tomaba las calles del país y que con su voz refrescante no fijaba límites al cambio.

Con todas estas piezas alineadas, Colombia dio un paso hacia un proceso constituyente por rutas democráticas ${ }^{9}$. El movimiento estudiantil movió la campaña de la "séptima papeleta", buscando la inclusión voluntaria por parte de la ciudadanía de una papeleta en las elecciones del Congreso de 1990 para demostrar el apoyo popular a una Asamblea Nacional Constituyente. La Corte Suprema de Justicia, a su turno, declaró constitucional el Decreto Legislativo 1926 de 1990, que convocaba la Asamblea Nacional Constituyente (Quinche Ramírez, 2008). Paradójicamente, este decreto lo había expedido el presidente de la República en virtud de uno de los problemas de la Constitución de 1886: el Estado de sitio ${ }^{10}$ (González Jácome, 2015; Valencia Villa, 1987). Los viejos problemas parecían abrir la puerta a las nuevas soluciones.

La Asamblea Constituyente se instaló el 5 de febrero de 1991. Durante su funcionamiento no cesaron los hechos de violencia en el país, lo que se reflejó en varias intervenciones de los constituyentes que resaltaban que mientras ellos discutían muchos colombianos sufrían la violencia y la injusticia. La emergencia

6 Algunos autores como Lemaitre y García Jaramillo resaltan el papel que cumplieron algunos profesores universitarios dentro del imaginario del movimiento estudiantil. Especialmente, el de Fernando Carrillo y de Eduardo Cifuentes, que para aquel momento era un joven profesor de la Universidad de los Andes.

7 Conviene recordar que la Corte Suprema de Justicia, en la Sentencia de mayo 5 de 1978, estableció que el art. 218 Superior, que regulaba la reforma constitucional de 1886, no podía ser modificado por el Congreso, ya que a este le estaba vedado el reformar sus propias competencias, y en particular esta, pues fue establecida por el constituyente primario en el plebiscito de 1957.

8 La rigidez en este caso era absoluta, pues no existía un mecanismo de reforma total de la Constitución. El contraste es la rigidez mínima como forma débil del constitucionalismo. Sobre este último aspecto véase:Melero (2020).

9 Hernando Valencia Villa realiza una crítica demoledora al constitucionalismo colombiano en su famoso libro Cartas de Batalla. En este texto Valencia muestra que las Constituciones anteriores a 1991 se utilizaban, en la práctica, como instrumentos de batalla para mantener el poder de un partido político. Eran instrumentos de dominación y contención política a favor del partido que las expedida, y por ende su diseño estaba ligado al ejercicio de este poder de contención.

10 “En Colombia pasamos de un Estado de sitio a un Estado social de derecho con la Constitución de 1991. De los 42 años previos a la Constitución el país vivió 37 en estado de sitio y, paradójicamente, la Asamblea Nacional Constituyente se convocó en virtud de un decreto de dicho estado de excepción". Ospina, 2020. La salud del estado de derecho ante la pandemia" (Ospina, 2020, párr. 1). Véase: Ospina, J. C. (10 de noviembre de 2020). La salud del estado de derecho ante la pandemia. Simposio «pandemia y constitución» (parte I). Recuperado de https://www.ibericonnect. blog/2020/11/simposio-pandemia-y-constitucion-la-salud-del-estado-de-derecho-ante-la-pandemia/ 
de la violencia sirvió como consenso político para elevar la necesidad de que la Constitución sirviera como un pacto de paz. Lemaitre (2012), en un corto pero potente estudio sobre la paz dentro de la Asamblea califica el consenso entre los constituyentes y, por ende, de la Constitución como un pacto de paz, como la paz retórica ${ }^{11}$. En palabras de Lemaitre (2012):

Así por ejemplo en la transcripción de los debates del artículo 22 en la Comisión Primera (pues el debate en Plenaria sobre este artículo es escaso) surge una concepción dominante de la paz que podemos llamar la "paz retórica", aquella de la cual todos están convencidos es el fin último de la Asamblea: la paz como propósito de toda la sociedad. Allí representantes de diversas corrientes ideológicas, tanto izquierdistas como liberales y conservadoras, intentan modular la paz en la Constitución como aspiración, anhelo, principio o valor, como uno de varios principios generales sin significado concreto que se refieren a esa aspiración compartida. (p. 6)

La "Constituyente por la Paz"12 tuvo como tarea construir los rieles para producir un cambio institucional estructural del país. Las garantías y los mecanismos de protección, así como la formulación de instancias para la promoción de los derechos humanos, tuvieron una particular confección. Las múltiples expresiones orgánicas y dogmáticas del texto constitucional son interdependientes e interrelacionadas.

Parece que la obviedad del acuerdo sobre la paz y la permanente reflexión pública sobre su importancia en el proceso constituyente produjo pocas reflexiones sobre su concreción en el texto constitucional. En los procesos democráticos los consensos se crean en donde están los disensos y la inclusión de fórmulas para la paz pasó sin una compleja confección. Las gacetas de la Asamblea Nacional Constituyente dejan ver reflexiones generales, como aquella que plantea que "La paz nacional e internacional es un derecho indeclinable del pueblo de Colombia"13 y que "Colombia repudia la guerra y la violencia como instrumentos de lucha por el poder o medio de solución de los conflictos internos ${ }^{\prime \prime 4}$. La reconstrucción del deseo y las aspiraciones sobre la paz se pueden concretar en la exposición de Guillermo Plazas Alcid:

la razón política para la viabilidad jurídica de esta Asamblea Nacional Constituyente se explica, entonces, por la necesidad de crear un meca-

11 La Corte Constitucional, desde muy temprano en su jurisprudencia, llamó a la Carta de 1991 como la Constitución para la Paz. La referencia más antigua se encentra en la Sentencia T-439 de 1992. Pero después de 27 años de funcionamiento esta referencia se mantiene en Sentencias como C-527 de 2017.

12 Intervención del constituyente Misael Pastrana Borrero ante la Plenaria de la Asamblea Nacional Constituyente. Enunciado en la Sentencia T-439 de 1992. MP Eduardo Cifuentes Muñoz.

13 Gaceta Constitucional n.o 36 de abril 4 de 1991. Ponencia de Álvaro Zalamea Acosta.

14 Gaceta Constitucional n.ำ 4. Jesús Pérez Gonzales proyecto de acto reformatorio de la Constitución n.ํำ 1 . 
nismo institucional idóneo, en el cual pudiera darse efectivamente la paz (...) la paz en estas condiciones estaría alcanzada, y la conquista de la paz constituiría la justificación política, jurídica e histórica de la existencia y acción de la Asamblea Nacional Constituyente.

Esta Asamblea tiene, pues, su origen en la urgencia de alcanzar la paz. Y si al término de sus tareas no se han sentado las bases de una paz real, efectiva y estable, dolorosamente tendríamos que aceptar desde ahora, que el pueblo colombiano está condenado, en lo que se refiere a la conquista de la paz, a compartir el frustrante destino de Sísifo. (Plazas Alcid, 1991, p. 3) 15 $^{15}$

La Constitución por la paz, pasados 30 años, puede medirse por sus promesas y por sus impactos. Las aspiraciones constitucionales han promovido cambios sustanciales en la forma como la ciudadanía se aproxima al Estado para exigir la protección de sus derechos, siendo los mecanismos constitucionales de protección una de las grandes conquistas sociales, y en la labor de las autoridades judiciales lideradas por la Corte Constitucional que se ha debatido, como ocurre con los procesos democráticos, entre momentos de apertura y cierre de garantías. Los impactos en esas materias son identificables en el funcionamiento de la acción de tutela.

No obstante, la frustración que produce el paso del tiempo en medio de la violencia, la repetición de los crímenes y el cierre de los caminos a la paz negociada, socavan la aproximación al cambio social derivado de la Constitución como un proceso. Si el cambio necesita tiempo, la sociedad necesita razones para la esperanza.

\section{Conflicto de aspiraciones: aproximaciones sobre el derecho a la paz}

En medio de un conflicto armado deteriorado y de una de las más graves situaciones de derechos humanos del mundo, aspirar a alcanzar la paz al inicio de la década de los 90 parecía una utopía. Los esfuerzos reales, pero limitados, por alcanzar acuerdos para el sometimiento de grupos armados, bajo la promesa de amnistías amplias e indultos inmediatos, eran insuficientes para consolidar transformaciones permanentes para la no repetición. El ciclo del conflicto en Colombia parece demostrar esta hipótesis.

En esa vía, entran en conflicto las aspiraciones y los límites que impone el derecho y el Estado para la construcción de una paz constitucional que conduzca,

Gaceta Constitucional n.ำ 16 de marzo 5 de 1991. Guillermo Plazas Alcid. 
en consecuencia, a cambios sociales. Los análisis ${ }^{16}$ sobre la literalidad del texto constitucional y la incapacidad o insuficiencia de transformación de sus promesas han acompañado las discusiones sobre los caminos para alcanzar la paz.

Resulta significativo que el artículo 22 de la Constitución, en donde se establece que la paz es un derecho y un deber de obligatorio cumplimiento, no haya sido objeto de una extensa discusión en la Asamblea Nacional Constituyente. Es significativo pues demuestra, como se anotó, que entre los miembros de la Asamblea existía un consenso para establecer este tipo de compromisos -que Lemaitre llama Paz Retórica- y, al mismo tiempo, no tomar decisiones de diseño constitucional para su realización.

De esta forma, el artículo 22 materializaba un consenso no peligroso para las posiciones mayoritarias que integraban la Asamblea. A pesar de que este artículo es la expresión más textual de la paz dentro de la Constitución, también hay otras referencias que toman la forma de convivencia en el preámbulo y en el artículo 2 , como fines de la Constitución y el Estado. En todos los casos se trata de referencias aspiracionales sin caminos expresos de concretización.

Hanna Lerner (2011), analizando la experiencia de sociedades profundamente divididas por razones identitarias y religiosas ${ }^{17}$, resalta los riesgos asociados a ver el diseño de una Constitución como un momento definitivo en donde se establece un modelo de Estado a través de una competencia de visiones sobre sus funciones y capacidades. Para Lerner (2011), en el proceso de diseño constitucional no es necesario, ni aconsejable, resolver todas las grandes preguntas con relevancia constitucional, menos en sociedades profundamente divididas. Esto puede dejar disposiciones constitucionales contradictorias, ambivalentes o ambiguas, aunque, al mismo tiempo permite cerrar el lapsus constitucional y empezar a regularizar estos dilemas dentro de la política ordinaria en un nuevo marco institucional. Lerner (2011), en este sentido, encuentra las virtudes de la ambivalencia y la ambigüedad dentro de las Constituciones, pues muestran los nudos constitucionales y las discusiones imposibles de saldar.

El lente que propone Lerner es interesante en sociedades conflictivas y divididas, aun cuando no sea una razón identitaria el centro de la disputa. En especial, porque las virtudes de la ambigüedad se presentan también como un mecanismo para que puedan convivir diferentes proyectos sobre un mismo asunto. En otras palabras, la virtud de lo ambiguo o ambivalente, en este caso, es que otorga plas-

16 Entre otros:Lee, I. D. (2018). El derecho a la paz en Colombia. Bogotá: Editorial Legis. Bernal, J., Parra, J., Sierra, H., Caldas, L. F., Andrade, J. y Zambrano, L. S. (2016). Reflexiones jurídicas sobre el proceso de paz. Bogotá: Editorial Universidad Externado de Colombia.

17 Una buena reflexión sobre las dificultades identitarias y religiosas en sociedades democráticas de corte liberal se encuentra en un reciente texto de Cristóbal Bellolio, titulado: Cartografías sobre el liberalismo. 
ticidad. Este enfoque, por ejemplo, se puede aplicar a los debates relacionados con la paz dentro de la Asamblea Nacional Constituyente para mostrar que el consenso sobre su importancia no implicaba, necesariamente, un acuerdo sobre su significado ni sobre los medios para alcanzarla. Se trató entonces de una discusión inacabada $\mathrm{o}$, tal vez, decantada en otros dilemas constitucionales.

El contenido del artículo 22 de la Constitución de 1991, así como las referencias finalísticas sobre la convivencia, no presentan ninguna disputa en los proyectos de paz que se posicionaron políticamente. Las consagraciones normativas normalmente deben estar acompañadas de un andamiaje institucional para que resulten transformadoras, para producir el cambio social. Las discusiones sobre instituciones como los estados de excepción, por ejemplo, resultan fundamentales para materializar un proyecto de paz y para potenciar o mitigar su capacidad transformadora. Igual ocurre con las capacidades concurrentes de distintas autoridades para la construcción de acuerdos de paz, entre otros.

Como lo muestra Barreto (2012), uno de los actos más interesantes de la Asamblea de 1991 fue desenmascarar el Estado de sitio de la Constitución de 1886 para evidenciar su cercanía con la figura del Estado de guerra, lo que resultaba incompatible con algunos proyectos de paz que se presentaban dentro de la Asamblea. Algo similar se puede evidenciar en discusiones de diseño constitucional que resultan relevantes para impulsar cambios sociales hacia la paz, en especial, porque los proyectos de transformación precisan para materializarse de declaraciones sujetas a mecanismos e instrumentos ${ }^{18}$. De esta forma, el consenso inicial sobre la paz y la Constitución como un medio para alcanzarla, debió servir de trampolín para discutir aquellos aspectos fundamentales que establecen los contornos y posibilidades de la paz dentro de la misma Constitución.

Según García Jaramillo (2015), durante la Asamblea era posible identificar al menos tres visiones de la paz: i) una centrada en la justicia distributiva, empujada principalmente por sectores alternativos; ii) otra enfocada en la inclusión política y democrática, relacionada con una propuesta liberal; y iii) la referida a un Estado fuerte con la capacidad suficiente para garantizar los derechos a través de la seguridad de sus ciudadanos. Estas diferencias no se veían afectadas por la inclusión del artículo 22, sino que se verterían en otras discusiones medulares, como el modelo de Estado social, los estados de excepción e incluso las funciones y competencias de los poderes del presidente.

Una crítica potente a las Constituciones que consagran derechos se encuentra en el famoso texto de Roberto Gargarella: La sala de máquinas de la Constitución: dos siglos de constitucionalismo en América Latina (1810-2010). En este texto, Gargarella crítica el constitucionalismo que pone su énfasis en la parte dogmática, en donde establecen los principios y derechos constitucionales, al tiempo que descuida la parte orgánica, en donde se reparte el poder público. El centro de la crítica consiste en que los derechos y principios constitucionales precisan de distribuciones adecuadas del poder para materializarse. 
Las tres versiones de la paz que se presentaron en la Asamblea estaban en competencia. Su discusión no se agotó en un solo momento, sino que se dio de forma incremental, prolongada y paulatina, por lo que los integrantes de la Asamblea en diferentes discusiones fueron dosificando e implicando las tres concepciones de la paz. Por esta razón, el conflicto de aspiraciones sobre la paz, que está presente en la Constitución de 1991, se explica por el entrelazamiento de los diferentes proyectos sobre de paz que tuvieron lugar en la Asamblea.

Con esta dinámica, cada posición debía ceder un poco para prevalecer y al mismo tiempo la promesa de paz que encarnaba la Constitución bebía de todas. Esto implicó el debilitamiento de todas las apuestas de paz de forma particular al ser remplazadas por un compendio que pudiera efectivamente integrarlas de manera ecléctica. Por ejemplo, el presidencialismo de la Constitución de 1991 es menos intenso que el de la Constitución de 1886, en parte, por la inclusión de nuevas instituciones que son capaces de frenar al presidente, como la Corte Constitucional. Sin embargo, el ejecutivo aún mantiene competencias amplias que le permiten imponerse a autoridades democráticamente electas a nivel local y desbalancear el sistema de frenos y contrapesos. En este sentido, el poder centralizado es legado, en cierta medida, por la apuesta conservadora de la paz dentro de la Asamblea que confiaba en un modelo de Estado fuerte, basado en una figura presidencial con amplias potestades, que además, pudiera imponerse desde el centro a las regiones en materia de seguridad, como vía para alcanzar la paz.

La promesa de la Constitución de 1991 concentró las aproximaciones de la paz en una apuesta como valor, principio, derecho y deber ${ }^{19}$. El compromiso de la paz, en este sentido, no es aislado sino estructural. El costo de esto es que se diluye la potencia de cada una de las apuestas de paz que se presentaron en la Asamblea, mitigando tanto sus defectos como sus virtudes. En este sentido, la potencia transformadora de la misma Constitución está relacionada con las posibilidades interpretativas que ofrecen las diferentes promesas de paz que la integraron.

Los matices entre justicia distributiva, convivencia, profundización e integración democrática y seguridad, a través del ejercicio legítimo de la fuerza, integran en su origen la promesa de la paz de la Constitución de 1991. Las diferentes manifestaciones de las promesas de paz consignadas en la Constitución producen conflictos en las aspiraciones, especialmente, en relación con el tiempo esperado para su materialización y los instrumentos para su encause.

El rendimiento del cambio social para la paz producido por la Constitución, requiere la aceptación de las disputas legítimas que se han construido frente a las manifestaciones constitucionales de la paz. No obstante, aceptar esto, no implica

19 Entre otras ver: Corte Constitucional, Sentencias C-379 de 2016, C-408 de 2017, C-007 de 2018, C-019 de 2018, T-365 de 2018 y C-069 de 2020. 
dejar de lado que hay unas manifestaciones básicas de la paz, que conforman el núcleo esencial, desde las cuales es posible desarrollar aspiraciones más complejas que generan un flujo deseable hacia lo posible.

\section{El imposible de la paz y la posible convivencia}

La esperanza en el Estado como proveedor de bienestar a partir de la garantía de los derechos humanos, se consolida en el uso de vías democráticas por parte de los ciudadanos para promover y exigir el cumplimiento de sus objetivos y fines (García, 2012). En este ejercicio democrático se encuentran tres enfoques presentes en los estudios de derecho y sociedad contemporáneos: i) el liberal tradicional, según el cual el derecho protege a los más débiles; ii) el marxista, según el cual el derecho legitima el poder y el statu quo; y iii) el ecléctico, que acepta que el derecho es un instrumento del poder y también un límite a los abusos de este, por lo que puede ser utilizado, tanto para oprimir como para proteger a los más débiles (Lemaitre, 2009).

El proyecto neoconstitucionalista se inscribe en el enfoque ecléctico, en tanto reconoce la potencia y los defectos del derecho. Pozzolo (1998), utiliza el término neoconstitucionalismo de forma descriptiva para referirse al surgimiento de nuevas Constituciones durante las décadas de los 80 y 90 . Ahora bien, el constitucionalismo, así como el neoconstitucionalismo, son denominaciones del modelo de Estado constitucional, es decir, la unión de instrumentos normativos e institucionales en un sistema jurídico-político históricamente determinado, que incluye la limitación de los poderes del Estado y la protección de los derechos humanos (Comanducci, 2002). Esta denominación ha sido objeto de análisis desde perspectivas teóricas, ideológicas y metodológicas (Carbonell, 2003).

El proyecto constitucional colombiano de 1991, heredero y muestra de algunas ideas neoconstitucionales, generó cambios en el diseño institucional, con la creación de la Corte Constitucional; en la forma en que se comprenden los derechos, con un enfoque garantista a partir de un amplio catálogo, que en todo caso no resulta taxativo para el reconocimiento de nuevos derechos; en el entendimiento de la Constitución como norma de normas, con un profundo proceso de constitucionalización; y en la labor de las autoridades judiciales, que promueven nuevas prácticas interpretativas y argumentativas, así como nuevos desarrollos teóricos (Comanducci, 2002; Guastini, 2001). Adicionalmente, la Constitución cuenta con características como la capacidad de invadir y condicionar el ordenamiento jurídico; la construcción de un proceso especial de movilización social; y la sensibilización de los jueces, la politización de la justicia y el activismo judicial (Agudelo, 2015; Guastini, 2003; Lemaitre, 2009). 
Todas estas características integran las expectativas en el funcionamiento adecuado del Estado para la garantía de los derechos humanos, consolidando una esperanza social sobre la Constitución, que García (2012) denomina: constitucionalismo aspiracional, el cual fortalece el reconocimiento de actores indispensables de cambios sociales y la comprensión de la movilización de los ciudadanos para la materialización de sus derechos. En alguna medida, esto se ve reflejado en los artículos 1 y 2 de la Constitución, ya que establecen que el Estado debe operar para dar respuesta a las necesidades de la sociedad. La relación simbiótica ${ }^{20}$ entre ciudadanía y Estado está construida constitucionalmente sobre esa esperanza ${ }^{21}$.

Estos elementos, que explican los contenidos constitucionales, permiten construir un puente entre aspiraciones y materialización. Así, es sugestivo que el andamiaje jurídico e institucional que propone el neoconstitucionalismo sea funcional a las sociedades que han experimentado graves violaciones de derechos humanos y que guardan profundas contradicciones. En parte, porque el horizonte aspiracional que contiene el proyecto neoconstitucionalista es gradual y se va desarrollando en el marco de una matriz que respeta los derechos, de tal forma que aun cuando se adelanten procesos de reconciliación siempre hay posibilidad de disentir. Esto es importante si se observa la experiencia de víctimas de graves y masivas violaciones de derechos humanos. Las reflexiones, como las de Jean Améry, sobre el resentimiento y su sentido político resultan útiles para mostrar como el proyecto neoconstitucional puede dar lugar a procesos de terminación de los conflictos y de reconciliación respetuosos.

En uno de sus textos más importantes, titulado: Más allá de la culpa y la expiación, Améry (2001), reflexiona sobre lo tormentoso que resulta avanzar por la vida cuando se han cometido actos tan atroces que hacen insoportable el presente de quienes sobrevivieron. Bajo estas condiciones se pregunta sobre las posibilidades de actos tan significativos como el perdón y la convivencia. Para Améry (2001), el perdón como obligación sería hipócrita, pues hasta que no se resuelvan las emociones que invaden el presente de la víctima -como el resentimiento-, no es posible el perdón. Al mismo tiempo, dado que el perdón es un don, es decir, es algo que se ofrece, depende únicamente de la voluntad de la víctima; en consecuencia, actos oficiales, como el perdón que otorga el Estado, resultarían efímeros. En cambio,

20 Concepto traído de la biología que nos sirve para plantear la relación estrecha, necesaria e indispensable entre ciudadanía y Estado. Sin ciudadanía no hay Estado y viceversa.

21 Esta expresión guarda relación con la utilizada por Duncan Kennedy sobre la pérdida de la fe o la renovación de la buena fe. Patricia Williams, en Williams, Brown y Jaramillo (2007), citando a Selznick señala que "En la discusión sobre el derecho, existe un conflicto que siempre se renueva entre aquellos que lo ven como una necesidad funcional y aquellos que invierten en él esperanzas y promesas. Los primeros aceptan el derecho como algo dado, un hecho, en el mejor de los casos como un instrumento práctico para resolver problemas. Para el idealista jurídico, por otra parte, el derecho connota un logro moral más amplio" (p. 57). También guarda relación con la utilizada por Sikkink (2018) frente al progreso de los derechos humanos basándose "no en un simple optimismo sino en una evaluación cuidadosa de la evidencia" (p. 28). 
la convivencia para Améry (2001), sería obligatoria. A diferencia del perdón, la convivencia es una obligación ética, un acto de disputa del presente ante las sombras del pasado. Pues una agresión por parte de las víctimas, incluso a pesar de las pulsiones justificadas que puede llegar a relajar las sensaciones, tiene el efecto perverso de empezar a aplanar la distancia entre las víctimas y los victimarios. Además, para Améry (2001), no hay nada más infame a que se acorte la distancia entre las víctimas y victimarios, sugiriendo que fueran equiparables aun a pesar de las montañas de cadáveres que los separan.

La distinción entre perdón y convivencia que se puede extraer de la obra de Améry (2001), es útil para mostrar un punto importante: las transformaciones en sociedades que intentan salir del conflicto -o en escenarios de posconflicto- deben basarse no en un ideal de reconciliación y perdón, sino en un ideal de convivencia que permita la vida colectiva, especialmente, entre víctimas y victimarios. La matriz que propone el neoconstitucionalismo resulta útil porque aspira a la reconciliación, pero busca garantizar la convivencia. La reconciliación y el perdón no solo son muy difíciles de probar y practicar, sino que transformar las sociedades en conflicto con base en este eje supone una exigencia que es en muchos casos antiética. En cambio, una transformación sustentada en la mera convivencia no solo aliviana las exigencias morales del cambio, sino que admite, de facto, la legitimidad de emociones como el odio, el resentimiento y el deseo de venganza, que son los elementos principales de los ciclos de violencia y que en ocasiones parecen respaldadas éticamente.

Améry escribe en un momento particular de la historia: cuando la República Federal Alemana empieza a sacudirse de su herencia nazi para tomar su lugar en las sociedades civilizadas del mundo, en un retorno desde la barbarie. En ese contexto, la distinción entre víctimas y victimarios es clara: toda la población que se había tragado la maquinaria de guerra nazi, frente al pueblo que aceitaba y empujaba esa maquinaria. Sin embargo, en otros contextos donde no es tan clara la distinción entre víctimas y victimarios, solo se refuerza la necesidad de fijar la convivencia, y no la reconciliación, como eje central de la transformación. Pues entre más confusa sea la distinción entre víctimas y victimarios, también lo será el sentido de la reconciliación, siendo más necesaria la convivencia. En otras palabras, la distinción entre víctimas y victimarios permite que opere la idea de un perdón y reconciliación direccionado: los victimarios ofrecen el perdón a las víctimas, quienes deciden otorgarlo; siendo este el presupuesto básico de la reconciliación. Sin embargo, si la distinción víctima/victimario es confusa resulta mucho más complicado que opere este mecanismo de reconciliación.

Cuando una sola persona se identifica como víctima y como victimario, el presupuesto para la reconciliación supone no solo el perdón sino el reconocimiento de responsabilidad por parte del contrario. El axioma cambia y resulta difícil que diferentes sectores de la sociedad admitan participar dentro de este 
juego de espejos si parte de sus capitales económicos, sociales, simbólicos y políticos se ven amenazados al reconocer esta responsabilidad. Esto se intensifica, en parte, porque como dice Mauricio García (2020), en este tipo de operaciones "se ponen a pelear las representaciones que cada uno se hace del ideario -o de sus responsabilidades y culpas- del otro" (p. 244). En este escenario la aspiración a la convivencia es profundamente significativa, aun cuando no tenga el brillo del anhelo contemporáneo de reconciliación.

La Constitución de 1991 refleja en alguna medida las virtudes de la convivencia, pues en ella persisten tres visiones sobre la paz que estuvieron en competencia durante la Asamblea -como se evidenció en el aparte anterior- (Lemaitre, 2009; García Jaramillo, 2015). La convivencia de estas visiones, que a su vez ha permitido que la paz adopte diversas formas jurídicas -principio, derecho, deber y valor, por ejemplo-, a pesar de que muchas veces son incompatibles, muestra las posibilidades que ofrece la misma convivencia.

El Acuerdo de Paz, que se integró a la Constitución con una fuerza jurídica relativa a través del Acto Legislativo 02 de 2017, más que un catalizador de todas las visiones sobre la paz que previamente integraban la Constitución, incorporadas en mayor o menor medida a los elementos de cada una de estas visiones, presenta una versión más potente de algo que ya se empezaba a gestar en la jurisprudencia de la misma Corte: la paz como garantía de los derechos de las víctimas y de la sociedad $^{22}$.

La versión de la paz que aporta el Acuerdo convive con las otras visiones sobre la paz que, en vez de invalidarse mutuamente dentro de la Constitución, se complementan. En este sentido, si la Constitución logró integrar tres visiones diferentes sobre la paz en su diseño original, la inclusión del Acuerdo termina aunando una visión que, a pesar de que asume compromisos particulares, no desaparece ni remplaza las visiones anteriores ni los compromisos constitucionales que estas asumen. El nexo que une todas estas visiones de paz es, de hecho, la convivencia: todas las visiones de la paz parten del núcleo común de la convivencia y desde ahí desarrollan sus particularidades y compromisos.

El Estado social de derecho y su mecánica de redistribución de recursos para alcanzar la paz social, se legitima en tanto nos beneficiamos de los frutos de la vida en sociedad, lo que presupone la convivencia; la inclusión y apertura democrática y política que reconoce la posibilidad y necesidad del diálogo entre iguales a partir de la convivencia; la visión de un Estado fuerte con capacidad para imponerse construida a partir de la valoración de la convivencia como un elemento asociado

22 La Sentencia C-574 de 2011, en la que se analiza si la Acto Legislativo 01 de 2009 -conocido popularmente como “Marco Jurídico para la Paz"- era o no una sustitución de la Constitución, permitió que la Corte Constitucional identificara como pilar fundamental e identitario de la Constitución la satisfacción de los derechos de las víctimas. 
a la seguridad; y la satisfacción de los derechos de las víctimas y la sociedad, lo que implica, como primera condición de posibilidad, la convivencia entre los titulares de esos derechos. Así, la convivencia sirve de punto de partida para todos los proyectos de paz y para el fortalecimiento del Estado de derecho y la democracia.

Una de las manifestaciones cotidianas de la paz es la convivencia. La Constitución, como se dijo antes, no es ajena a esta visión pues consagra en el preámbulo y en el artículo 2 la convivencia como una manifestación de la paz. Estas referencias que consagran una idea básica, que también ha sido menos referenciada jurídicamente por la potencia jurisprudencial del artículo 22, valoran algo que es muy importante: la cotidianidad de la vida colectiva. Ligar la convivencia a un fin esencial del Estado supone, por sí misma, establecer la necesidad de que sea cotidiano, de que suceda siempre.

En este sentido, si asumimos que la precondición de la paz es la reconciliación, estaríamos, como argumenta Améry (2001), posicionándonos frente a la necesidad de que víctimas y victimarios resuelvan sus dilemas para que opere una transformación social -o incluso, para afirmar que esta transformación existe o es valiosa-. En cambio, si asumimos que la precondición de la paz es la convivencia, además de generar un espacio de libertad para que se resuelvan o no los dilemas entre víctimas y victimarios, también dejamos una textura abierta, una cierta plasticidad, para que se desarrollen de forma conjunta diferentes proyectos de paz.

Paradójicamente, uno de los recursos más valiosos que tienen las sociedades democráticas es la capacidad para transformarse a sí mismas. Pasados de abusos y violencias rompen la capacidad de transformación de una sociedad y congelan su plasticidad, tal vez instando a que los dilemas que surjan alrededor de este pasado se resuelvan en un momento definitivo con tal precipitación que no se contribuye a acrecentar la transformación sino a disminuir esta plasticidad. En cambio, la convivencia, a mediano plazo, tiene la posibilidad de volver a regular lo básico para cualquier proyecto de paz ${ }^{23}$. Los 30 años de la Constitución de 1991, antes que un proceso de reconciliación para el cambio social, muestra un proceso incremental de transformación que busca que la convivencia agregue visiones transdiciplinarias y múltiples proyectos de paz, entre estas, la incorporada por el Acuerdo Final de 2016: la paz transicional de los derechos de las víctimas con vías para la convivencia y la no repetición.

23 Hay diferentes aproximaciones conceptuales al concepto de paz. El trabajo de Johan Galtung (1990), que identifica la violencia cultural, por ejemplo, es un modelo interesante de quienes piensan la paz únicamente como la ausencia de violencia directa, sin tener en cuenta otros tipos de exclusión, discriminación y marginalización presentes en muchas sociedades. Una parte de la paz redistributiva y de la paz como inclusión política, que estaban en la Asamblea Nacional Constituyente, mostraban una sensibilidad por disminuir la violencia cultural, además de crear las condiciones para la ausencia de violencia directa. La convivencia, que también es un eje de este texto, reconoce la violencia cultural y en alguna medida zanja el camino para superarla a través del pacto de no retroceso frente a la violencia directa. 
En la aparente imposibilidad de la paz ofrecida desde 1991 y la posible convivencia que reconoce la diversidad y la necesidad de la existencia compartida, se encuentra una solución al conflicto de aspiraciones derivada de las múltiples aproximaciones a la paz. Si bien la violencia y los eufemismos nos arrebataron la palabra convivir del lenguaje disponible en esta materia, la convivencia debe surgir como una apuesta integral para el cambio social. De acuerdo con el artículo 2 del Decreto Ley 588 de 2017, que organiza la Comisión para el Esclarecimiento de la Verdad, la Convivencia y la No Repetición, la convivencia:

no consiste en el simple compartir de un mismo espacio social y político, sino en la creación de un ambiente transformador que permita la resolución pacífica de los conflictos y la construcción de la más amplia cultura de respeto y tolerancia en democracia. (Presidente de la República, Ley 588 de 2017)

El diálogo como regla básica de la vida en sociedad, la dignificación de las víctimas, el reconocimiento de la violencia y sus impactos, y la verdad como fuerza de cambio, pueden producir condiciones de respeto en la diversidad y confianza en el otro, la cooperación y la solidaridad como elementos esenciales para el fortalecimiento democrático. Con estos elementos posibles, quedará libre el camino del cambio social frente a la desigualdad y la injusticia social, asuntos que alimentan la indiferencia y la resistencia que alimentan los ciclos de violencia. Ahora bien, la convivencia requiere el respeto, la garantía, el ejercicio y la protección de los derechos humanos como una condición básica para materializarse.

\section{Razones para la esperanza y la desesperanza}

La literatura, durante la primera década posterior a la Constitución de 1991, era entusiasta del nuevo derecho, a partir de una expectativa derivada del cambio normativo, y de la renovación jurídica que se vivió desde la materialización de derechos -algunos, incluso, calificaron a estos años como la revolución de los derechos (López Medina, 2004)-. Parecía que la Constitución había despertado una ola de esperanza (Lemaitre, 2009). El entusiasmo soportado en el fetichismo legal y la confianza en la Constitución se mantenía aún a pesar de que en ese periodo de tiempo se intensificó el conflicto armado. Ariel Ávila (2019), por ejemplo, dice que los 90 e inicios de los 2000 fueron los peores años del conflicto, lo que es fácilmente verificable con los datos del Registro Único de Víctimas durante ese periodo.

Después de 30 años, 56 reformas constitucionales, una profusa e innovadora jurisprudencia constitucional y varios procesos de transición, parece necesario reforzar la esperanza en el cambio social. Esto contrasta con sus logros, como la cercanía con los ciudadanos, especialmente por medio de las acciones constitu- 
cionales, y la progresividad en la reivindicación de los derechos humanos. Uno de los centros de la desesperanza es la aparente incapacidad de la Constitución para alcanzar la promesa de paz, yendo más allá de las declaraciones, y garantizar la convivencia y tranquilidad en el territorio. Es la desesperanza de una promesa incumplida.

Sin embargo, valorar como incumplida la promesa de paz es un síntoma de lo Sikkink (2018), llama "una comparación con lo ideal" (p. 54). Para Sikkink (2018), hay dos formas para evaluar si un derecho, como la paz, es efectivo o se ha materializado. La primera, es empirista: implica realizar una indagación a través de diferentes elementos -como datos o estadísticas- para establecer si la consagración normativa ha afectado o incrementado el goce de la población. La segunda, es idealista: implica consagrar un ideal regulativo deseable y examinar si la consagración normativa ha permitido un acercamiento a este ideal regulativo.

En esa vía, los acuerdos de sometimiento de grupos armados, como el de 2005 y el acuerdo de paz de 2016, dan razones para la esperanza, a pesar de los profundos debates sobre su incumplida implementación. La búsqueda de condiciones para la convivencia y la no repetición son razones de esperanza en medio de la desigualdad y la injusticia social, porque materializan los caminos del diálogo que la violencia ha cerrado una y otra vez.

Si la implementación del Acuerdo de Paz de 2016, amplio e integral como fue confeccionado, es una política de Estado ${ }^{24}$ y las futuras aproximaciones frente a la paz deben reconocerla como un objetivo constitucional de carácter esencial, es posible que los compromisos de cambio social tengan espacio en el abordaje complejo, matizado y espaciado que requiere su concreción. Enfrentar los problemas fundamentales del Estado de derecho, como la grave situación de derechos humanos y los riesgos en el funcionamiento del sistema de frenos y contrapesos, así como de la debilidad democrática, son apuestas sustanciales por el cambio.

Adicionalmente, las contribuciones a la verdad sobre lo ocurrido en el conflicto armado, los diálogos para la formulación de garantías para la no repetición y las iniciativas para el fomento de la convivencia, a partir de la formación de ciudadanos informados sobre los pormenores de la historia de violencia, de los silencios y de las huidas, dan entrada a espacios en los que la existencia colectiva se viabiliza y la corresponsabilidad se gestiona.

Es posible que algunas promesas constitucionales sigan siendo incumplidas, por la ausencia de políticas públicas para la materialización de las promesas y las utopías, pero el ejercicio de los derechos y el empoderamiento de los territorios son caminos apropiados para que germine la esperanza. En esa vía, la reforma rural 
integral y las iniciativas de apertura democrática en dirección territorio-nación conllevan una disposición para la convivencia.

En contraste, el cierre de las puertas al diálogo como solución a los conflictos, el deterioro de la situación de derechos humanos, el asesinato de líderes y lideresas sociales, así como de personas defensoras de derechos humanos y excombatientes que apostaron por la paz, son especialmente preocupantes. Estas razones para la desesperanza acompañan las reflexiones y evaluaciones sobre el cumplimiento de las promesas de la Constitución a sus 30 años. Nos aturde el ruido de la violencia mientras valoramos un proceso de madurez constitucional indispensable para delinear el futuro.

Adicionalmente, el incumplimiento de los acuerdos con grupos sociales, comunidades y territorios, así como el reducido impacto de las medidas de restitución y distribución de tierras, generan las condiciones para que se reciclen los conflictos y sigan sin atención las condiciones que producen la desigualdad estructural y la debilidad democrática.

La cuestión de la desigualdad, vinculada directamente con la idea de distribución y redistribución, tradicionalmente ha girado alrededor de dos ámbitos: una posición liberal de la economía que deja al mercado y a la iniciativa individual las posibilidades de mejora de las condiciones de vida, con una limitada y restringida intervención del Estado, y una posición socialista, según la cual solo las luchas sociales y políticas, con actuación del Estado, puede llegar hasta la médula del proceso de producción para cuestionar las desigualdades (Piketty, 2015, pp. 9-10).

Como lo señala Vilhena (2011), la desigualdad social extrema y persistente, que se traduce en exclusión social y económica, erosiona la imparcialidad legal y la reciprocidad, provocando la invisibilidad de los más pobres, la demonización de quienes cuestionan el sistema y la inmunidad de los privilegiados, lo que deteriora la integridad del Estado de derecho.

Así, la lucha contra la desigualdad que se presenta en los Estados como una disputa contra la pobreza requiere nuevos puntos de vista para producir cambios sustanciales, que podrían ser adoptados por la ciudadanía y las autoridades, como los vinculados al concepto de desigualdad estructural. Se trataría, en este caso, de rechazar una utopía mínima de los derechos humanos (González Jácome, 2019 , p. 17), construida mientas se desactivaba la guerra fría y se iba erigiendo el periodo de reformas del mercado o de los Estados neoliberales, y promover una utopía de máximos en la que la desigualdad tenga cabida en las preocupaciones humanitarias.

Como lo señala Moyn (2019), la revolución de los derechos humanos ha fracasado en responder o incluso en reconocer su incapacidad para eliminar las causas estructurales de la desigualdad sostenida por el neoliberalismo, porque 
se ha enfocado, principalmente, en los abusos policiales y se ha dedicado, cuando es más ambiciosa, en establecer garantías de provisión suficiente a través de referencias a la pobreza.

Una nueva mirada de las aspiraciones de cambio social a 30 años de la Constitución no solo es necesaria, sino que debe acompañar los nuevos diálogos para la transformación y la materialización de las promesas. Hay que cumplir las promesas para alimentar las esperanzas.

\section{Conclusiones}

Luego de 30 años, el cambio social para la paz sigue en gestación. La convivencia es la paz posible, a partir de una comprensión pragmática de la Constitución y el compromiso social con los derechos humanos. A pesar de las promesas incumplidas y de las transformaciones sociales incompletas, no es poco tener instrumentos políticos y jurídicos orientados a la convivencia, pues estas aspiraciones constitucionales mueven los deseos de cambio social.

La construcción constitucional sobre la paz y sus distintas aproximaciones generó un conflicto de aspiraciones que aún es visible y según el cual la paz es un todo o un nada, sin espacio para los matices, los tiempos y los procesos. El perdón y la reconciliación, por ejemplo, son aspiraciones deseables, pero son procesos que no pueden asegurarse ni verificarse. Si asumimos que estas aspiraciones son los indicadores de la paz, la convertimos en un imposible y en una fuente de desesperanza. Esto no implica negar el gigante desafío que supone la desigualdad para la convivencia, ni el incumplimiento de las promesas constitucionales, sino valorar las razones para la esperanza.

\section{Referencias bibliográficas}

Agudelo, C. A. (2015). La democracia de los jueces. Bogotá: Editorial Leyer.

Améry, J. (2001). Más allá de la culpa y la expiación: tentativas de superación de una víctima de la violencia. Valencia: Pre-textos.

Ávila, A. (2019). Detrás de la Guerra en Colombia. Bogotá: Planeta.

Barreto, A. (2012). La generación del Estado de sitio: el juicio a la anormalidad institucional colombiana en la Asamblea Nacional Constituyente de 1991. Precedente. Revista Jurídica, 1, 9-48.

Bernal, J., Parra, J., Sierra, H., Caldas, L. F., Andrade, J. y Zambrano, L. S. (2016). Reflexiones jurídicas sobre el proceso de paz. Bogotá: Editorial Universidad Externado de Colombia. 
Bonilla, D. (2015). Constitucionalismo del sur global. Bogotá: Siglo del Hombre Editores. Carbonell, M. (2003). Neoconstitucionalismo(s). Madrid: Trotta.

Colombia. Corte Constitucional. (22 de julio de 2011). Sentencia C-574/11. [MP Juan Carlos Henao Pérez].

Colombia. Corte Constitucional. (18 de julio de 2016). Sentencia C-379/16. [MP Luis Ernesto Vargas Silva].

Colombia. Corte Constitucional. (28 de junio de 2017). Sentencia C-408/17. [MP Gloria Stella Ortiz Delgado].

Colombia. Corte Constitucional. (11 de octubre de 2017). Sentencia C-630/17. [MM. PP. Antonio José Lizarazo y Luis Guillermo Guerrero].

Colombia. Corte Constitucional. (1 de marzo de 2018). Sentencia C-007/18. [MP Diana Fajardo Rivera].

Colombia. Corte Constitucional. (4 de abril de 2018). Sentencia C-019/18. [MP José Fernando Reyes Cuartas].

Colombia. Corte Constitucional. (4 de septiembre de 2018). Sentencia T-365/18. [MP Alberto Rojas Ríos].

Colombia. Corte Constitucional. (19 de febrero de 2020). Sentencia C-069/20. [MP Cristina Pardo Schlesinger].

Colombia. Presidente de la República. (abril 5 de 2017). Decreto 588 de 2017. Por el cual se organiza la Comisión para el Esclarecimiento de la Verdad, la Convivencia y la no Repetición. Diario Oficial n. 50.197.

Comanducci, P. (2002). Formas de (neo)constitucionalismo: un análisis metateórico. Isonomía Revista de Teoría y Filosofía del Derecho, (16), 89-112.

De Gamboa, C. y Uribe, M. (2017). Los silencios de la guerra. Bogotá: Editorial Universidad del Rosario.

Duncan, G. (2015). Más que plata o plomo. El poder político del narcotráfico en Colombia y México. México D.F.: Debate Eds.

Fonnegra González, M. (1988). El plebiscito de 1988. Revista Facultad de Derecho y Ciencias Políticas, (82), 174-201. Recuperado de https://revistas.upb.edu.co/ index.php/derecho/article/view/4786

García, M. (2012). Constitucionalismo aspiracional: derecho, democracia y cambio social en América Latina. Análisis político, 25(75), 89-110.

García, M. (2020). El país de las emociones tristes. Una explicación de los pesares de Colombia desde las emociones, las furias y los odios. Bogotá: Ariel.

García Jaramillo, L. (2015). Constitucionalismo deliberativo. Estudio sobre el ideal deliberativo de la democracia y la dogmática constitucional del procedimiento parlamentario. México: Universidad Nacional Autónoma de México. 
González Jácome, J. (2015). Estados de Excepción y Democracia Liberal en América del Sur: Argentina, Chile y Colombia 1930 y 1990. Bogotá: Editorial: Pontificia Universidad Javeriana.

González Jácome, J. (2019). Revolución, democracia y paz. Trayectorias de los Derechos Humanos en Colombia (1973-1985). Bogotá: Tirant lo Blanch.

Galtung, J. (1990). Cultural Violence. Journal of Peace Research, 27(3), 291-305.

Guastini, R. (2001). Estudios de teoría constitucional. México. UNAM.

. (2003). La "Constitucionalización" del ordenamiento jurídico: el caso italiano. En: Carbonell, M. (Coord.). Constitucionalismo(s). Madrid, Editorial Trotta.

Kennedy, D. (2002). The Critique of Rights in Critical Legal Studies, in Brown and Halley, eds., Left Legalism/Left Critique. Duke University Press.

Lee, I. D. (2018). El derecho a la paz en Colombia. Bogotá: Editorial Legis.

Lemaitre, J. (2009). El Derecho como conjuro. Fetichismo legal, violencia y movimientos sociales. Bogotá: Universidad de los Andes, Siglo del hombre editores.

Lemaitre, J. (2012). La paz en cuestión: la guerra y la paz en la Asamblea Constituyente de 1991.SELA, 1-32. Recuperado de https://www.law.yale.edu/sites/default/ files/documents/pdf/sela/SELA12_Lemaitre_CV_Sp_20120325.pdf

Lemaitre, J. (2019). El Estado siempre llega tarde. La reconstrucción de la vida cotidiana después de la guerra. Bogotá: Siglo Veintiuno Editores, Universidad de los Andes.

Lerner, H. (2011). Making Constitutions in Deeply Divided Societies. Cambridge: Cambridge University Press. DOI: 10.1017/CB09780511793394

López Medina, D. (2004). Teoría Impura del Derecho. La transformación de la cultura jurídica latinoamericana. Bogotá: Legis, Universidad de los Andes.

Melero de la Torre, M. (2019). La rigidez constitucional mínima como una forma débil del constitucionalismo. Isonomía - Revista de Teoría y Filosofía del Derecho, (51), 65-94.

Moyn, S. (2015). La última utopía. Los derechos humanos en la historia. Bogotá: Editorial Pontificia Universidad Javeriana.

Ospina, J. C. (10 de noviembre de 2020). La salud del estado de derecho ante la pandemia. Simposio «pandemia y constitución» (parte I). Recuperado de https://www. ibericonnect.blog/2020/11/simposio-pandemia-y-constitucion-la-saluddel-estado-de-derecho-ante-la-pandemia/

Piketty, T. (2015). La economía de las desigualdades. Cómo implementar una redistribución justa y eficaz de la riqueza. Argentina: Siglo XXI Editores.

Plazas Alcid, G. (5 de marzo de 1991). Esta es la Constituyente del Consenso «Si bien esta Asamblea es heterogénea en su composición política, podrá ser homogénea en sus propósitos nacionalistas». Gaceta Constitucional n.ํㅜ 16 . Recuperado de https://babel.banrepcultural.org/digital/collection/p17054coll26/id/3812 
Quinche Ramírez, M. F. (2008). Derecho Constitucional colombiano de la Carta de 1991 y sus reformas. Bogotá: Universidad del Rosario.

Sikkink, K. (2018). Razones para la Esperanza. La legitimidad y efectividad de los derechos humanos de cara al futuro. Buenos Aires: Editorial Siglo XXI.

Valencia Villa, H. (1987). Cartas de Batalla. Una crítica del constitucionalismo colombiano. Bogotá: Universidad Nacional de Colombia.

Vilhena, O. (2011). Desigualdad estructural y Estado de derecho. En: Rodríguez, C. (coord.) El derecho en América Latina. Un mapa para el pensamiento jurídico del siglo XXI. Buenos Aires: Siglo Veintiuno Editores.

Williams, P., Brown W. y Jaramillo, I. (2007). La Crítica de los Derechos. Bogotá. Siglo del Hombre, Universidad de los Andes e Instituto Pensar. 